Int. J. Electrochem. Sci., 13 (2018) 2299 - 2309

International Journal of

ELECTROCHEMICAL

SCIENCE

WWw.electrochemsci.org

\title{
Synthesis of Au-modified Reduced Graphene Oxide Supported Pd-Ni nanocomposites and electrocatalytic activity for propane- 1,3-diol oxidation
}

\author{
Xudong Huang ${ }^{1}$, Tianci Niu ${ }^{2}$, Yujie Shi ${ }^{3}$, Yan Jiang ${ }^{*}$ \\ Jiangsu Key Laboratory of Advanced Catalytic Materials and Technology, Changzhou University, \\ Jiangsu 213164, People's Republic of China \\ *E-mail: jy@cczu.edu.cn
}

doi: $10.20964 / 2018.03 .59$

Received: 6 November 2017 / Accepted: 5 January 2018 / Published: 5 February 2018

\begin{abstract}
A Reduced Graphene Oxide-Supported $\mathrm{Pd}-\mathrm{Ni}$ nanocomposite $\left(\mathrm{Pd}_{1} \mathrm{Ni}_{4} / \mathrm{RGO}\right)$ was prepared by simultaneous chemical reduction, on the surface of which a small amount of Au nanoparticles were subsequently deposited via potentiontatic deposition to obtain an Au-deposited $\mathrm{Pd}_{1} \mathrm{Ni}_{4} / \mathrm{RGO}$ (denoted as $\mathrm{Au}_{(\mathrm{x})}-\mathrm{Pd}_{1} \mathrm{Ni}_{4} / \mathrm{RGO}, \mathrm{x}=1,2$, and $5 \mathrm{~s}$, representing the deposition time of $\mathrm{Au}$ ). As a representative, the surface structure of the $\mathrm{Au}_{(1 \mathrm{~s})}-\mathrm{Pd}_{1} \mathrm{Ni}_{4} / \mathrm{RGO}$ electrode was characterized and analyzed by scanning electron microscopy (SEM), transmission electron microscopy (TEM), energy dispersive X-ray spectrum (EDX) and X-ray diffraction (XRD), respectively. The modification approach described here is simple, effective and versatile, which can be further used to modify other metal substrates with an additional metal. Moreover, the Au deposition induces a positive effect on the electro-catalytic activity for propane-1,3-diol oxidation in alkaline media in comparison to the $\mathrm{Pd}_{1} \mathrm{Ni}_{4} / \mathrm{RGO}$.
\end{abstract}

Keywords: nanocomposite; electrocatalytic activity; electrode; catalyseis.

\section{FULL TEXT}

(C) 2018 The Authors. Published by ESG (www.electrochemsci.org). This article is an open access article distributed under the terms and conditions of the Creative Commons Attribution license (http://creativecommons.org/licenses/by/4.0/). 